\title{
UPGRADED SUSTAINABILITY, INCLUSIVENESS AND VALUE ADDITION OF THE COTTON VALUE CHAIN. COLLABORATIVE INNOVATION BETWEEN ITALY AND EGYPT ABOUT SUSTAINABILITY
}

\author{
Dalia Gallico \\ Università San Raffaele Roma, Via Daverio 7 Milano - via Val Cannuta 247 Roma Italy
}

\begin{abstract}
In response to the challenges posed by sustainable development and in line with the 2030 agenda which promotes the multi-stakeholders approach as the only one which can enhance the achievement of the Sustainable Development Goals (SDGs), the project seeks to promote inclusive and sustainable development of the textile industry and enhance the cotton's contribution to the Egyptian economy, employment and manufacturing value added and export growth by actively engaging the private sector (CSR, investors, partners, mentors, etc.), develop business partnerships, and leverage non-traditional funding. Moreover, as the proposed project puts the promotion of sustainable and inclusive growth at the centre of its action, particular emphasis is placed on addressing economic and social inclusiveness and active involvement of vulnerable groups (poor, women, youth, rural communities). The project contributes improving farming environment (non-toxic and biodiverse), developing sector specific technical and entrepreneurial opportunities and the ability to capture business opportunities in National and international markets, thus contributing to better and more secure livelihoods for target beneficiaries and their households.

Final consumers, in national and international markets, are also indirectly benefit from the proposed project as a result of the efforts exerted to preserve the quality and sustainability of the Egyptian cotton and strengthen its competitiveness.

Important collaborative innovation between Egypt and Italy for new scenarios and concept design.
\end{abstract}

\section{KEYWORDS}

Sustainable Development, Sustainable Agriculture, Education, Active Involvement, Environment, Textile, Cotton

\section{INTRODUCTION}

Cotton is the world's oldest commercial crop and one of the most important fibre crops in the global textile industry. It is grown in more than 100 countries on $2.5 \%$ of the world's arable land - some 35 million hectares - making cotton one of the most significant crops in terms of land use after food grains and soybeans. Cotton is also a heavily traded agricultural commodity with over 150 countries involved in exporting or importing it.

Cotton plays a major role in the economic and social development of developing and newly industrialized countries. There are millions of people worldwide who derive their livelihood from cotton's value chain, which involves several stages like research and development, cultivation, extraction of fibres, primary processing of the fibre for marketing, secondary processing of the fibre to yarn, dyeing and other processing to convert the yarn to fabrics, making clothes and garments. Furthermore, millions of people are employed in the associated activities of trading and transportation. As many as 100 million rural households $-90 \%$ of them living in developing countries - are directly engaged in cotton production. An estimated 350 million people work globally in the cotton sector when family labour, farm labour and workers in connected services such as transportation, ginning, baling and storage are taken into account. The global garment and textile industries alone employ 60 million to 75 million people worldwide. Likewise, cotton and the textile industry play a significant role in the Egyptian economy.

Egyptian cotton has historically represented the gold standard for the world's finest linens and clothing. 
Egypt's extra-long staple cotton (Gossypium barbadense), often called the "White Gold", is grown in the moist atmosphere near the Nile. The Egyptian cotton is among the finest and most lustrous varieties and the highest quality fibre. The quality is due to a few things. First, Egyptian cotton is generally handpicked in order to avoid mixing the mature and immature plants. Secondly, it has exceptional length and brightness. The longer the fibre, the better the textile quality as it means less breakage and more uninterrupted thread. Therefore, the Egyptian cotton is widely used by luxury and upmarket brands.

Egypt's textile industry has historically been considered of paramount importance to the country and its economy. Currently the Egyptian textile industry contributes to 3\% of the country GDP, accounts for one third of the manufacturing value added, employs almost one third of Egypt's industrial workforce, and it's responsible for 15\% of Egypt's non-oil and gas exports (worth 2.6 billion USD).

Nonetheless, as recently outlined by the "Vision 2025 Expansion \& Employment - Egypt textile National strategy" Egypt still plays a marginal role in the global textile value chain as its textile industry is highly fragmented and its textile products do not meet the needs and requirements of the international market.

Despite the efforts made by the Egyptian Government in the last years, the situation with regard to both the competitiveness of the Egyptian lint cotton and readymade garments remains critical. The industry suffers from lack of renovation, high input prices, limited skilled labour, and scarce innovative and sustainable agricultural practices.

Spinning and weaving are the main feeding sectors for the textiles industry. Most spinning and weaving capacity is owned by medium- to large-scale public-sector companies, although the private sector is slowly entering the segment. Dyeing and finishing are the weakest points in the value chain, with the least amount of investments. Public-sector dominance of spinning and weaving has limited producers'responsiveness to consumer preferences and burdened the sector with over employment, inferior technology, operational inefficiencies, and low levels of capital utilization. Moreover, linkages between spinners and ready-made garments producers are weak at best.

As a result, some yarns and finished fabrics are imported from India, Turkey, Turkmenistan,Bangladesh, Pakistan, and other countries to feed the ready-made garment industry. Some finished fabrics are made of Egyptian cotton, processed abroad, and re-exported to Egypt.

Egypt exports long staple (LS) and extra-long staple (ELS) cotton, as well as garments (52.8\% of exports) mostly based on imported yarns, and finished fabrics and home textiles ( $25.4 \%$ of exports) made from local yarns/ fabrics. $75 \%$ of raw cotton exports are sent to low cost, textile countries (e.g. India, Pakistan, China) where raw cotton is processed into added-value yarns, fabrics, garments (e.g.100\% Egyptian cotton shirts made in India). Egypt imports relatively cheaper medium staple types for the textile and clothing industry.

The public-owned companies failed to compete with imported materials and products, losing market shares. As a result, many firms declined, turning off several production lines.

Egypt, that had initially seen an increase in area and production from 1940s to 1970s, experienced a gradual production drop since 1980s as well as gradual decrease in consumption that shifted to cheaper, lower-quality fibre and fabrics like polyester. A substantial decline occurred in domestic sales and exports alike. As a consequence, and in light of the difficulties in marketing domestic cotton crops, thousands of Egyptian farmers, have turned away from cotton in favor of other crops, for both domestic markets and for export. With the growing increase in imports (clothing, dyes and supporting material for the industry) compared to exports, the result was an overall negative trade balance. The textile and clothing industry became a drain of foreign exchange resource rather than a source of income.

\section{COTTON PRODUCTION IN EGYPT}

The decline in production is strictly related to the contraction of the foreign demand. Such decline in exports of lint cotton is due to the perceived degrade in quality, both in terms of seeds impurity and cotton lint contamination. Cleanliness and contamination depend on harvesting methods, handling, storage, transport and ginning practices. Contamination of lint by non-vegetable substances is one of the major problems especially with handpicked cotton. As a matter of fact, contaminated cotton causes disruptions in the spinning process hence such cotton is normally sold at considerable discount to compensate the spinner company of the additional costs incurred. 
With reference to the organic cotton production, this still represents a very minor percentage of the overall cotton production in Egypt, despite the competitive advantage of the Egyptian natural endowments and the potential benefits and profitability of penetrating the growing niche market of sustainable agriculture. The global demand for organic cotton has been steadily growing in the last years as an increasing number of brands have made commitments to use 100\% organic cotton by ambitious target dates, often 2020 . Benefitting from this international trend would require building a more sustainable and integrated supply chains starting with raw materials and fibre production as well as actively promoting and sustaining new and innovative business models by fostering collaboration between big and small brands, local producers and national and international mills.

In an effort to restore international markets' confidence about the quality of the Egyptian cotton, the Government of Egypt has recently undertaken relevant normative reforms, namely: i) the Ministerial decree number 1918/2015, which identifies the conditions for qualifying seeds for planting and reintroduced the Government full ownership of seed production and distribution, and the establishment of a monitoring system covering the entire supply chain of licensed Egyptian cotton holders under the umbrella of the Cotton Egypt Association (CEA). In addition, the Government, through the Cotton Research Institute has also planted selected cotton seeds from high quality lint in an area of 12,600 ha in eight governorates which produced 41,237 bales of cotton. The Ministry of Agriculture and Land Reclamation (MALR) declared its intention to conduct another round of seeds purification to improve the quality and expects that around $60 \%$ of the seeds produced are going to be used for the 2016/17 crop.

Despite the forecasted total increase, production of ELS is expected to continue its downward trend.

\section{COTTON INDUSTRIAL TRANSFORMATION IN EGYPT}

While Egyptian cotton is famous worldwide for its long staple, which allows it to be spun and woven into luxurious fabrics, getting the true value out of the long staple cotton requires updated and sophisticated technologies. By contrast, most of Egypt's textile factories are equipped with outdated machineries not suitable to manufacture Egyptian ELS cotton. Indeed, the consumption projection for the year 2015/16 estimates a consumption of lint cotton equal to 590,000 bales and local spinners are expected to obtain $70 \%$ of their cotton requirements from imports and the remaining from local cotton production.

Coupled with the above mentioned challenges is the lack of skilled human resources. In spite of the ongoing efforts of the Government of Egypt and the international community, notably through the EU TVET initiatives (I and II), to revamp and update the Technical and Vocational Education and Training System, there is still a substantial mismatch between the education system's outputs and the labour market requirements. According to Annual Global Competitiveness Report 2015-2016 released by the World Economic Forum, Egypt ranks 131 out of 140 nations for the overall quality of the education system (with similar rankings for math/science and management education), and 117 for innovation.

Such persistent dearth of skilled workers and general managers is particularly marked for the industrial and the agricultural sectors. There is, in fact, a clear lack of horizontal integration between the agricultural and the industrial training path, resulting in a misperception of the complex interaction of the different actors of the cotton value chain, as well as a tendency to the segmentation of knowledge and limited coordination between education institutions and market operators.

Building on the continuous support received by UNIDO on promoting industrial development and on recent achievements related to employability, value chains and private sector development, the Ministry of Trade and Industry requested UNIDO to extend the collaboration to support the textile value chain.

Given the above scenario and in line with UNIDO's mandate of promoting industrial development for poverty reduction, inclusive globalization and environmental sustainability, UNIDO is proposing the implementation of the project "From cotton seeds to clothing: Enhancing the sustainability, inclusiveness and value addition of the cotton value chain in Egypt" which aims at improving the economic, social and environmental performance of cotton growers and processors while strengthening support institutions.

The proposed project has been designed to build upon the ongoing CSR initiative "Cottonforlife", implemented by FILMAR S.p.A. in cooperation with Alexbank, to further integrate the scope of intervention and scale up the impact of the Cottonforlife Initiative in order to upgrade the whole value chain, reach out to a larger number of producers and exporters, and build the capacities of the institutions involved. 
Cottonforlife is an integrated five-year program aimed at promoting sustainable fashion through a transparent, eco-friendly and socially responsible Egyptian cotton textile production. The Initiative has managed, through agreements signed between the private sector and farmers' associations, Ministry of Agriculture and Ministry of Education, to trigger plantations of organic ELS Egyptian cotton (Giza 45 and Giza 87) and has produced a unique and extra-fine organic yarn, called NILO, which has been presented in the most important international fairs and has received a great response from International buyers and most renowned Italian brands. The Initiative has also invested in human resources development, through an earmarked co-funding of Alexbank which has committed to support the initiative for five years, by supporting agricultural and industrial textile schools to enhance horizontal integration between the agricultural and the industrial training path. Activities implemented ranged from curricula development to training of trainers and publication of updated textbooks for the 3 years school paths.

\section{MAIN TARGET GROUPS}

The proposed project seeks to define and pilot innovative and sustainable solutions to be applied to the different gaps and shortfalls along the whole LS and ELS cotton value chain. The project's activities are addressed to the following target groups reaching out to at least 1,000 direct beneficiaries:

- Cotton growers and cotton growers' associations, that will benefit from knowledge sharing and capacity building with regards to the adoption of sustainable agricultural practices for organic and non-contaminated cotton and better market linkages;

- Private sector textile enterprises including SMEs and youth-led start-ups (involved in spinning, weaving, knitting, dyeing and/or finishing, garment manufacturers), whose productive and export capacity, social and environmental performance will be enhanced;

- Traders and retailers, that will benefit from improved practices in terms of product certification and traceability mechanisms as well as from enhanced coordination and exchange of information between national and international actors;

- Agricultural workers as well as technicians and professionals employed in textile enterprises, whose skills will be enhanced to meet labour market needs, through updated educational and training offer and on-the-job training;

- Students enrolled in secondary technical agricultural and industrial schools and/or attending vocational training programs, whose skills will be enhanced to meet labour market needs, through updated educational and training offer and on-the-job training;

- Technical support institutions and specialized centres, which will benefit from exchange of expertise and capacity building activities.

Moreover, as the proposed project puts the promotion of sustainable and inclusive growth at the centre of its action, particular emphasis is placed on addressing economic and social inclusiveness and active involvement of vulnerable groups (poor, women, youth, rural communities). The project contributes improving farming environment (non-toxic and biodiverse), developing sector specific technical and entrepreneurial opportunities and the ability to capture business opportunities in National and international markets, thus contributing to better and more secure livelihoods for target beneficiaries and their households.

Final consumers, in national and international markets, are also indirectly benefit from the proposed project as a result of the efforts exerted to preserve the quality and sustainability of the Egyptian cotton and strengthen its competitiveness.

\section{STAKEHOLDERS}

The proposed project, in line with UNIDO approach and mandate, will adopt a multi-stakeholders approach building on the existing network and modalities of cooperation already established through the ongoing CSR initiative "Cottonforlife". 
UNIDO promotes the active engagement of MALR and the Ministry of Trade and Industry (MTI) as main counterparts, as well as their affiliated institutions, with the aim to leverage their efforts for the enhancement of the Egyptian cotton production and industrial transformation and improve their capacities to set up a conducive regulatory environment for eco-friendly and socially responsible cotton production and industrial transformation.

MALR and its affiliated specialized centres and institutes, namely: The Agricultural Research Center (ARC). Established in 1970 with the overarching goal of maximizing the economic return per unit of land and water.

The Cotton Research Institute (CRI). By adopting a multi-disciplinary approach, the CRI seeks to enhance collaboration among cotton breeders, agronomists and technologists for the development of new varieties of seeds that fulfil the needs of domestic and International spinners. CRI activities aim at pursuing the following long-term objectives: developing new cotton varieties ensuring increased productivity and tolerance to climate events and pest whilst preserving genetic purity of seeds; improving quality assessment techniques and developing agronomic practices to enhance cotton yields and quality; identifying the most suitable agroclimatic zones for better spin ability; developing cotton classification and grading techniques and improving ginning techniques to better meet the needs of domestic and export markets.

o The Central Laboratory of Organic Agriculture (CLOA). It is mandated to promote organic agriculture practices in line with international standards, reduce the use of pesticides and other contaminating substances, monitor and issue certification for farms and organic products and conduct capacity building activities to increase awareness about organic agricolture techniques and practices.

The project seek the engagement of MTI-related institutions representative of the industry and specifically the textile industry, i.e. the Egyptian Council for Textile Industries, the Industrial Modernization Center (IMC), the Federation of Egyptian Industries (FEI) and its Textile chamber, the Textile Export Council and Home Textile Export Council serving as forums for dialogue between national and international yarns and fabric importers and investors in the fields of spinning, weaving, dyeing and finishing with the final aim of strengthening the competitiveness of the Egyptian exports in foreign markets. The project also seeks engagement of the Textile Technology Center (TTC), the Egyptian Organization for Standardization and Quality control (EOS), The Productivity \& Vocational Training Department (PVTD), the Fashion Design Center (FDC). FDC is a collaborative effort between MTI and the Italian Istituto di Moda Burgo (Milan) and is one of the most recently established centres in Egypt which provides students with an high quality educational offer (both diploma and short-term courses) in the field of fashion and design in line with international standards. FDC also makes its facilities available on a fee-basis to incubate fashion entrepreneurs, and provides consultations and services (such as collection design) to Egyptian factories.

In addition, The Egyptian Cleaner Production Center (ENCPC) is also involved in activities related to the promotion of resource efficiency and cleaner production (RECP) and renewable energy, and the Productivity and Quality Enhancement Center (Kaizen) in activities related to control and improvement of productivity and quality of manufacturing.

Similarly, by leveraging Filmar's network, synergies with Italian institutions representative of the Italian textile and fashion industry (e.g. Italian Chambers for fashion and design, Italian Association of Textile machinery producers, Unionfiliere, Unioncamere and Italy's Chambers of Commerce) as well as Egyptian and international textile companies and brands will be promoted to facilitate exchange of know-how and best practices, including with regards to quality and standardization, traceability, technological innovation, product design and marketing. The already existing partnership with Alexbank will enhance activation of start-ups through concrete possibilities of access to funding.

Additional key stakeholders include specialized technical associations, such as the Cotton Arbitration and Testing General Organization (CATGO), the Alexandria Cotton Export Association (ALCOTEXA), the Cotton Egypt Association (CEA): CATGO is the national independent body providing arbitration and technical services (moisture control, classing and grading services, etc.) for all operators in the textile value chain. CATGO pursues three main objectives: maintaining the purity of the Egyptian cotton varieties by preventing all forms of mixing varieties and/or grades; controlling and supervising all cotton handling processes starting from harvesting to local spinning and export and preventing all forms of mixing and contamination; and iii) providing technical assistance to concerned parties in both seed and lint cotton production and issuing recognized certificates for classing cotton, fibre testing and moisture regain. 
ALCOTEXA is the non-profit and non-trading organization of Egyptian exporters, including cotton trading and ginning companies. As a regulative authority ALCOTEXA has the mandate of formulating export policies and setting sales prices (indicative or minimum). Membership of ALCOTEXA is mandatory for all companies willing to trade cotton in Egypt.

CEA, created by MTI and ALCOTEXA, is the sole representative of the registered trademark logo and licensing authority to certify the authenticity of the Egyptian cotton through DNA analysis, in an effort to ensure quality and contrast the marketing of forged products.

The Ministry of Education was also be engaged as a coordinating partner for the project's activities targeting agricultural and industrial secondary schools and TVET centres. Similarly, synergies with national and international education and training institutions (e.g. University of Alexandria and the Don Bosco Institute of Alexandria, Italian and international academic institutes and renowned fashion and design centres) will be promoted with regards to curricula development and training of trainers.

\section{RATIONALE}

The potential for local processing of Egyptian cotton is still mainly untapped - the bulk of it is exported as a basic commodity. Some of the items produced have $70 \%$ imported component simply because feeding and raw material industries are not established.

The spinning of cotton yarn represents the first stage in the industrial transformation of raw cotton into an intermediate textile product (yarn), and results in significant value addition.

Cotton yarn is an industrial commodity that is widely traded on the world market. Over 30 countries participate in the international trade in cotton yarn. Unlike finished textile articles, yarn is not influenced by changes in fashion and style because it is an intermediate product in the textile production chain.

Yarn can be stored for long periods. The cotton yarn market is highly sensitive to shifts in demand for and supply of cotton at the international level.

World trade in cotton yarn is estimated at eight billion US dollars, so the market represents an attractive option for cotton-producing countries. The trade in cotton yarn offers a unique competitive opportunity with regard to China because China does not compete as much with other yarn producing countries as it does with countries that produce other fabrics and garments. In fact, China is the largest importer of cotton yarn in the world.

From a development perspective, promoting the spinning industry helps integrate the Egyptian economy into global value chains.

For Egypt to become a solution provider of middle and upper market textile products, supplying EU, US, Arab and African retailers and manufacturers with quick service and delivery of both finished products and intermediary textiles, and for the Egyptian textile industry to contribute to the growth of the national economy, create new employment and income generating opportunities, and increase its share in the global markets, the Vision 2025 sets an action plan to achieve the following objectives:

- Create 1 million new job opportunities for skilled and semi-skilled workers;

- Train over 500,000 workers and managers as well as adding engineering diplomas for 100,000 technical managers;

- Increase exports to 10 billion USD using 70\% of locally manufactured raw material;

- $\quad$ Additional investments of over 13.5 billion USD in the industry.

In order to upgrade the Egyptian textile industry and integrate it into the global economy, the Vision 2025 identifies, inter alia, the following main strategic pillars, with focus on both finished products and primary textiles:

- Expand the industrial base through developing and enhancing the competitiveness of the local industry;

- Foster backward vertical integration, promoting investments into primary textiles and fibre production;

- Foster export's growth and market entry;

- Strengthen human capital development;

- Promote policy change and investment in infrastructure to unleash the growth potential of the industry. 
Business models are changing, pushing the textile supply chains in new directions where the sine qua non condition is to build cooperation and integration of actors along the whole value chain. The international markets and consumers are focused more and more on transparency and traceability requirements, underpinning the need to build sustainable supply chains starting from the very beginning: raw materials and fibre production. In this light, new business models need to be implemented through collaboration between farmers, spinners, weavers and big and small brands, to develop strategies and production models around sustainability, fairness and transparency of textile value chain.

The decline in the production of the Egyptian cotton, strictly related to the contraction of the demand, and the ensuing decline of the Egyptian textile industry in terms of both production and exports signal that the industry should implement more advanced and susteinable approaches to compete internationally and meet market and buyers requirements, by attracting new private investment in order to equip itself with skilled labour and technologically advanced machinery and production lines. The proposed project aims, therefore, at contributing to build local capacities to improve the productivity, competitiveness, inclusiveness and sustainability of the Egyptian cotton growers and processors, promote business linkages and partnerships, innovation and human capital development, and ultimately better position the Egyptian cotton in domestic and export markets.

\section{COMPARATIVE ADVANTAGE}

The project benefits from and capitalize on UNIDO's technical competence and experience in enhancing agro-industrial value chains in Egypt, as well as in modernizing the cotton-textile-garment (CTG) value chains - from the processing of raw materials to producing textiles and ready-made apparel and improving market access, quality and certification infrastructures - in South Asia, Latin America, West and Central Africa (jointly with WTO) and the South Mediterranean region. Additionally, UNIDO's best practices in sustainable consumption and production (through RECP measures) in the South Mediterranean region and the promotion of renewable energy for industrial applications in Egypt will be leveraged.

In response to the challenges posed by sustainable development and in line with the 2030 agenda which promotes the multi-stakeholders approach as the only one which can enhance the achievement of the Sustainable Development Goals (SDGs), the project seeks to promote inclusive and sustainable development of the textile industry and enhance the cotton's contribution to the Egyptian economy, employment and manufacturing value added and export growth by actively engaging the private sector (CSR, investors, partners, mentors, etc.), develop business partnerships, and leverage non-traditional funding.

In order to foster the cotton production, its conversion into yarn, and expanding the cotton-based textile industry in Egypt, the project makes the integration of two complementary strands of action: Improve the economic performance, inclusiveness and sustainability of cotton growers (particularly of LS and ELS cotton).

Improve the economic performance, inclusiveness and sustainability of private sector textile enterprises (processors of LS and ELS cotton, including SMEs and youth-led start-ups). The proposed strategies are in line with UNIDO's approach on agro-value chain development, inasmuch as agro-value chain development has a positive impact on employment, including in rural areas (off farm processing and income diversification), offers market access to smallholders, and creates business linkages to small and medium enterprises (SMEs). A value chain describes the entire range of activities undertaken to bring a product from the initial input-supply stage, through various phases of processing, to its final market destination, and it includes its disposal after use. Accordingly, segments of the value chain to be targeted are prioritized based on their proven potential for local value addition (local content and processing), profitability, inclusiveness and sustainability.

As part of its efforts to build national capacities along the whole cotton value chain, the project intends to strengthen the capacities of the existing support institutions to set-up a conducive regulatory environment for eco-friendly and socially responsible cotton production and industrial processing.

By developing and implementing the above strategies in close coordination with existing government and non-government support institutions, UNDIDO intends to: 
- Benefit, directly and indirectly at least 1,000 individuals depending on the cotton value chain

- Improve access to employment / entrepreneurial opportunities in the cotton value chain

- Support the increase of the productivity and competitiveness of cotton growers, ginneries and textile enterprises

- Promote the increase of export revenue

- Facilitate investment in the cotton processing industries

- Promote the increase of cotton value added

- Promote more efficient use of resources in both cotton production and processing.

\section{COTTON SUSTAINABLE PRODUCTION}

Based on lessons learned from similar ongoing initiatives implemented by Filmar in Egypt and on international agricultural best practices, the project raises awareness of LS and ELS cotton growers and deploy demonstration pilots on suitable options to improve cotton cultivation with regards to organic plantations, low contamination, and more efficient use of water, fertilizers and pesticides, and preservation of soil health. Technical sessions and on-the-job training will be complemented with study tours in order to increase both growers' technical knowledge and capacity to adopt sustainable agricultural practices, as well as their understanding of the market and buyers' requirements through direct contacts with immediate consumers of their cotton, i.e. spinning mills.

Organic cotton, using natural rather than chemical inputs, pesticides and fertilisers, is environmentally sound, regenerates soil fertility, avoids contamination of land and water and is healthier for farmers and rural communities themselves as it is based on organic inputs and fertilisers that are less likely to poison or contaminate users.

Unsustainable agricultural practices that rely heavily on agrochemicals will be discouraged. Cotton farmers rely heavily on agrochemicals such as herbicides to eradicate weeds and pesticides as well as to control the numerous pests, which are estimated to destroy around 15 percent of the world production. The consequences of uncontrolled use of agrochemicals include deterioration in soil quality and productivity, contamination of groundwater, increasing resistance of pests, negative effects on biodiversity, health risks for farmers.

In this regards, farmers' awareness on adequate protective equipment and the consequences of the utilization of hazardous chemicals will be raised. Integrated pest management approach and an emphasis on the use of pest control techniques other than pesticide application will be promoted in order to reduce reliance on pesticides.

Additionally, the adoption of efficient water management practices, that help optimize water use, maximise productivity, and minimise cotton's environmental impact, as well as soil management practices, that maintain and enhance the structure and fertility of the soil and minimize erosion and whereby nutrients are applied on the basis of the crop and soil needs, will be promoted.

Furthermore, value addition activities, including processing and marketing of cotton seed by-products, are identified and promoted, thus contributing to increasing the income of cotton growers and hence improving their livelihoods.

Increasing numbers of individual consumers as well as large companies, especially in niche markets, have become interested in certified organic cotton, in improving the quality of their supplies in conformità with international requirements, and in maintaining the social standards within the value chain and are ready to pay the higher price.

Quality is, therefore, a prerequisite for trade and market access.

Problems during any step of production or processing can cause irreversible damage to fibre quality and reduce profits for the producer as well as the segments of the textile industry including spinning, weaving, dyeing, and finishing: the efficiency of the gin are affected by the level of trash and contamination of the seed cotton, and the quality and therefore value of yarn that can be spun is directly related to the quality of the lint cotton delivered to the spinning mill.

Practices for harvesting, managing and storing seed cotton so as to minimize trash, contamination and damage will be promoted. Knowledge and skills of target cotton growers will be upgraded with regards to 
quality standards, quality control and quality assurance systems, and laboratory testing procedures, for their cotton production to better match buyers' quality requirements and international standards.

Ginners, classifiers, breeders and traders will be trained on the development, preservation, characterization of the quality and classification of the cotton fibre.

An integral part of the efforts towards improved quality will be directed to strengthen the capacities of the MALR and its affiliated institutions ensuring conformity of the production with quality requirements and international standards. An action plan and technical guides for improvement of the Egyptian organic cotton quality (standards for quality, growing, ginning and classification of cotton, and good trade practices for cotton) will be developed and disseminated.

Transparency and traceability are also required more and more by buyers and consumers. The project builds on the best traceability practices implemented by Filmar for the production of Nilo. Filmar is one of the certified companies in the framework of the Italian Traceability \& Fashion scheme, managed by Unionfiliere and promoted by Unioncamere and Italy's Chambers of Commerce. It creates a voluntary certification scheme providing transparent information to consumers on: locations of the main production stages of the production chain; the health values supporting the product, how environmentally friendly the product is and the manufacturer's social responsibility.

Moreover, the cotton growing sector suffers from the shortage of research to breed new cotton varieties and increase the yield per feddan. In addition to enhancing quality control and assurance, the capacities of the MALR and its affiliated institutions with regards to cotton-related agricultural polizie is enhanced with a view on improving existing cotton varieties and developing new ones (organic cultivation and low contamination, seed purification, development of new hybrids) based on market demand and related certification, including by promoting the participation of the private sector in the experimental cotton plantation. In order to contribute to reduce the cotton stocks and make the cotton trends and requirements of national and international markets.

Improving seed quality, cotton productivity, its quality and cleanness prior to raw fibre sales, transparency and traceability contributes to breaking the cycle of the deterioration of the Egyptian cotton quality and better positioning it in the markets. Cotton growers and relevant institutions are now, further, in the promotion and branding of non-contaminated and organic cotton in selected destination markets.

Finally, based on sustainable agricultural practices deployed, the project, in close cooperation with the private sector, develops / updates training offers (including in-company practical training, internships, exchanges) targeting TVET students and trainers to ensure training offers are more respondent to labour market requirements.

\section{CONCLUSION}

The importance of moving up the value chain is illustrated by the percentage of the value added at each step of the CTG value chain, which increases with the level of processing.

In line with the government priority to enhance the role of private entrepreneurship in the textile industry and unburden the sector from the public spinners and weavers and their outdated technology and inefficient production, the present project aims to identify and promote local value addition in terms of local content and processing, as well as related investment opportunities for downstream processing to ensure that Egyptian cotton yarn is processed domestically instead of being exported as lint cotton, which will also provide new and better employment and income opportunities to the local communities and hence better and more secure livelihoods.

This was achieved through the provision of technical and business support services to LS and ELS cotton processors in order to improve their technical, technology, managerial and marketing capacities (supply chain management, production management, technology management, responsiveness to consumers' preferences nationally and internationally), as well as matching with investors and funding opportunities.

In addition to a sound analysis of the value chain, to compete better all actors in the value chain need a better understanding of destination markets and consumers. Therefore, opportunities for the promotion of the LS and ELS Egyptian cotton in national, regional and international markets are identified, including through the established network of Filmar and its business linkages with high-end buyers in niche markets as well as on other networks of private sector companies. In addition, market familiarization missions to 
cotton-consuming countries are organized to learn what their clients expect from them and to promote their products.

Given that quality, as previously mentioned, is a prerequisite for trade and market access, cotton processors' awareness and skills about quality of cotton processed goods, process control techniques in spinning, weaving, dyeing and finishing, and testing of cotton processed goods will be enhanced.

Moreover, building on UNIDO's activities in Egypt and elsewhere aiming at promoting sustainable consumption and production patterns, the project also raises awareness on and support target enterprises in the adoption of RECP measures for rationalizing the use and improving the re-use of water, energy, chemicals and other resources, starting from metering resource consumption, which will result in less adverse environmental impacts and will help the enterprises make savings on resources.

Special attention are given to industrial wastewater treatment, as the textile industry, and specifically dyeing, is high water consuming, and to the promotion of productive uses of textile waste including through innovative upcycling models.

The absence of skilled labour and national technical expertise constitutes another obstacle to the competitiveness of the Egyptian textile industry. The Egyptian textile industry needs to be supported by an efficient and updated education and training system given that physical capital in the absence of human capital provided by efficient education and training is of less value. The present project intends, therefore, to contribute to providing the textile sector with skilled young entrepreneurs and managers as well as the necessary trained technical labour with integrated competences and skills ranging from cotton cultivation to the production of yarns and fabrics as demanded by the industry. Filmar's and Alexbank's ongoing initiative to update training offers in industrial schools will be leveraged, and parallel efforts will be exerted to build industry support services by upgrading technical and entrepreneurial skills for local advisory services to serve the textile industry and promote new and creative fashion design solutions (including but not limited to product design and marketing, garment modeling, innovative upcycling of textile waste, export promotion).

The project will not only provide technical and business support services to individual enterprises but also support networks / clusters. For enterprises, especially SMEs, to be able to overcome sector-level constraints and therefore increase their competitiveness, inter-firm cooperation within clusters is another important enabler of development and innovation. Clustering allows for a concentration of resources and funding in targeted areas with a high growth and development potential that can spread beyond the target locations (spill-over and multiplier effects). Clustering provides enterprises with access to specialized suppliers and support services, experienced and skilled labour and the knowledge

sharing that occurs when people meet and talk about business. Clusters are particularly promising environments for SME development. Due to their small size, SMEs individually are often unable to realize economies of scale. Within clusters, SMEs can realize shared gains through the organization of joint actions between cluster enterprises (e.g., joint bulk inputs purchase or joint advertising, or shared use of equipment) and between enterprises and their support institutions (e.g., provision of technical assistance by business associations or investments in infrastructure by the public sector).

Specifically, the project will facilitate joint market access and promotional activities, business partnerships with exporters and retailers, synergies with technical support institutions, fashion centres and academia to reinforce production, technological innovation, creativity and export capacities.

Building on UNIDO's accumulated expertise in developing and upgrading industrial zones and parks, the project will also identify, in close coordination with national public and private stakeholders, the need for textile industrial zones / parks and develop related technical and financial feasibility studies.

In addition to upgrading and developing supply and productive capacities, the project, in close coordination with the MTI and its affiliated institutions, will promote the development of sectoral strategies and policies, which constitute another main determinant of enhancing the competitiveness of the cotton and textile industry. Special regards will be given to the identification of public-private partnership models not only in in spinning and weaving but also in the printing and dyeing sectors because of the large investment cost involved.

Awareness and technical and operational capacities of MTI and its affiliated institutions will be strengthened with regards to the services provided to the textile industry by the project to ensure competitive and sustainable cotton processing (technological innovation, quality control and assurance, RECP, innovative product design and marketing, and export promotion) and its conformity to market requirements and international standards. 


\section{REFERENCES}

Better Cotton Initiative, 2013. Better cotton production principles and criteria explained.

COMESA, 2009. Regional Strategy for developing the cotton, textile and clothing manufacturing, marketing and distribution/exporting.

Cotton commodity briefing, FairTrade and Cotton, March 2015

Gazanfer, 2007. Identification of strategies for developing the cotton value chain in West and Central Africa-Based on a comparative study on India, Turkey and Egypt. Textile Industry in Egypt... great infrastructure but absence of good management practice. German - Arab Trade. Issue Three 2015 vol. 66 no. 3.

Gherzi, 2012. Vision 2025 Expansion \& Employment - Egypt textile national strategy.

GTZ SME Promotion Programme, 2004. Textile desk research. Value chain analysis preparation phase.Prepared by Context Consulting \& Services.

Hussein K., 2008. Cotton in West and Central Africa: Role in the regional economy \& livelihoods and potential toadd value. Proceedings of the Symposium on Natural Fibres. The decree stipulates that seeds should not be allowed for planting if the degree of genetic purity is less than 99.5\%, if Gassypium Hirsutum L (upland cotton) seeds are found, if the germination percentage is less than $72 \%$ and if the agricultural value is less than $70 \%$.

UNECA, AU, 2013. Economic report on Africa 2013. Egypt country case study.

UNIDO, 2009. Agro-value chain analysis and development. The UNIDO approach, a staff working paper.

UNIDO, 2009. Globalization, the changed global dynamics of the clothing and textile value chains and the impact on ub-Saharan Africa. Research \& Statistics Branch, Working Paper 10/2008.

UNIDO, Gherzi, 2011. Feasibility study for a cotton spinning mill in 11 sub-Saharan African countries.

USAID, 2009. Improving Productivity in Egypt's Ready-Made Garments Sector. Trip Report.

USDA Foreign Agriculture Services, April 2016. Egypt. Cotton and Products Annual 2016, Gain report. http://www.coop.ch/content/dam/act/taten/tat-193/2013\%20TE\%20Organic\%20Cotton\%20Summary.pdf http://www.tfashion.camcom.it/

http://www.globalstandard.org/https://www.oekoex.com/en/business/certifications_and_services/ots_100/ots_100_start.x html

http://www.kering.com/en/magazine/picking-thread

http://www.solidaritycenter.org/wp-content/uploads/2015/11/Global.Garment-Workers-Fact-Sheet.11.15.pdf 